\title{
Relationship between chronic kidney disease and metabolic syndrome: current perspectives
}

This article was published in the following Dove Press journal:

Diabetes, Metabolic Syndrome and Obesity: Targets and Therapy

18 September 2014

Number of times this article has been viewed

\author{
Khaled Nashar' \\ Brent M Egan ${ }^{2}$ \\ 'Division of Nephrology and \\ Hypertension, Allegheny General \\ Hospital, Pittsburgh, PA, USA; \\ ${ }^{2}$ Care Coordination Institute \\ and Greenville Health System, \\ Greenville, SC, USA
}

\begin{abstract}
Both metabolic syndrome (MetS) and chronic kidney disease (CKD) are increasing in incidence and lead to significant cardiovascular morbidity and mortality. The relationship between these two entities is complex. Individual components of the MetS are known risk factors for incident kidney disease, but it is not clear how the clustering of these components is linked to the development and progression of kidney disease. Cross-sectional studies show an association of the MetS and prevalent CKD; however, one cannot draw conclusions as to which came first - the MetS or the kidney disease. Observational studies suggest a relationship between MetS and incident CKD, but they also demonstrate the development of MetS in patients with established CKD. These observations suggest a bidirectional relationship. A better understanding of the relationship between components of the MetS and whether and how these components contribute to progression of CKD and incident cardiovascular disease could inform more effective prevention strategies.
\end{abstract}

Keywords: obesity, insulin resistance, hypertension, oxdative stress, inflammation, adipokines

\section{Introduction}

The clustering of elevated blood glucose, hypertension, and hyperuricemia was first noted in $1923 .{ }^{1}$ Subsequently, obesity, hypertension, and elevated blood glucose were observed in patients who were at risk of developing diabetes. ${ }^{2}$

The term syndrome $\mathrm{X}$ was first used in $1988 .{ }^{3}$ It was believed that insulin resistance was the pathophysiological common denominator underlying this cluster. The term metabolic syndrome (MetS) later replaced syndrome X. Several definitions were proposed for the MetS. The most widely accepted definition was issued by the Adult Treatment Panel III of the National Cholesterol Education Program (NCEP-ATPIII). According to the NCEP-ATPIII definition, MetS is defined as having three or more of the following five risk factors including: 1) abdominal obesity defined by waist circumference (men $>102 \mathrm{~cm}$; women $>88 \mathrm{~cm}$ ); 2) triglycerides $\geq 150 \mathrm{mg} / \mathrm{dL} ; 3$ ) low highdensity lipoprotein (HDL) cholesterol levels (men $<40 \mathrm{mg} / \mathrm{dL}$; women $<50 \mathrm{mg} / \mathrm{dL}$ ); 4) blood pressure $\geq 130 / \geq 85 \mathrm{mmHg}$; and 5) fasting glucose $\geq 100 \mathrm{mg} / \mathrm{dL}$. ${ }^{4}$

The MetS is linked prospectively with incident diabetes mellitus, stroke, and other cardiovascular events. ${ }^{5}$ Moreover, the MetS is also linked to the development of fatty liver, hyperuricemia/gout, polycystic ovarian syndrome, gallstones, and sleep disorders. ${ }^{6}$ According to the third National Health and Nutrition Examination Survey (NHANES III) criteria, about 47 million people have MetS. This is about $24 \%$ of the US adult population, including $44 \%$ in people over 50 years of age. ${ }^{7}$ 
The prevalence of the MetS varies widely worldwide and rises with economic development and the associated overweight and obesity as seen among populations in Asia, South America, and Eastern Europe. MetS statistics depend on the definition used. ${ }^{8}$

The 2002 definition of chronic kidney disease (CKD) was recently updated by the Kidney Disease: Improving Global Outcomes (KDIGO) Group. CKD is classified based on cause, glomerular filtration rate (GFR) category, and albuminuria category (Tables 1 and 2). ${ }^{9}$

It is estimated that 26 million American adults have CKD and millions of others are at increased risk. In addition to leading to end stage renal disease (ESRD), CKD increases the risk of death, cardiovascular events, and hospitalization. This risk rises sharply with an estimated GFR (eGFR) less than $45 \mathrm{~mL} / \mathrm{min} / 1.73 \mathrm{~m},{ }^{2}$ with risk of mortality particularly high with eGFR values below $15 \mathrm{~mL} / \mathrm{min} / 1.73 \mathrm{~m}^{2} .^{10}$

In a systematic review of 39 studies that included a total of more than a million patients, Tonelli et al demonstrated an increased relative risk of all-cause mortality in nondialysis-dependent CKD patients. The absolute risk of death appeared to increase exponentially as renal function declined. ${ }^{11}$

The MetS is associated with a twofold increase in cardiovascular events, ${ }^{12}$ stroke, ${ }^{13}$ and in all-cause mortality. ${ }^{12,14}$ Outcomes studies in the setting of CKD and MetS comorbidity are limited. Data from the multiethnic study of atherosclerosis reported that the combination of CKD (defined as eGFR $<60 \mathrm{~mL} / \mathrm{min} / 1.73 \mathrm{~m}^{2}$ ) and MetS (defined by the NCEP-ATPIII) is a strong predictor of incident cardiovascular events (myocardial infarction, cardiac arrest, angina, stroke, cardiovascular related death), adjusted hazard ratio (HR) 5.56 (95\% confidence interval [CI] 3.72-8.12). ${ }^{15}$

In a study of 545 consecutive patients who underwent percutaneous coronary intervention, cardiovascular events (cardiovascular death, nonfatal myocardial infarction, revascularization for target and new lesions) occurred more frequently in patients with both MetS and CKD than those with CKD or MetS (51.4\%) (log-rank $P<0.001$ ). After adjusting for confounders, both MetS and CKD

Table I Albuminuria categories in CKD

\begin{tabular}{lll}
\hline Category & $\begin{array}{l}\text { Albumin/creatinine } \\
\text { ratio }(\mathbf{m g} / \mathbf{g})\end{array}$ & Terms \\
\hline Al & $<30$ & Normal to mildly increased \\
A2 & $30-300$ & Moderately increased \\
A3 & $>300$ & Severely increased \\
\hline
\end{tabular}

Abbreviation: CKD, chronic kidney disease.
Table 2 GFR categories in CKD

\begin{tabular}{lll}
\hline $\begin{array}{l}\text { GFR } \\
\text { category }\end{array}$ & $\begin{array}{l}\text { GFR } \\
\left(\mathbf{m L} / \mathbf{m i n} / \mathbf{l . 7 3 2} \mathbf{~ m}^{\mathbf{2}}\right)\end{array}$ & Terms \\
\hline GI & $\geq 90$ & $\begin{array}{l}\text { Normal or high } \\
\text { G2 }\end{array}$ \\
G3a & $60-89$ & $\begin{array}{l}\text { Mildly decreased } \\
\text { Mildly to moderately } \\
\text { decreased } \\
\text { Moderately to }\end{array}$ \\
G3b & $45-59$ & $\begin{array}{l}\text { severely decreased } \\
\text { Severely decreased } \\
\text { Kidney failure }\end{array}$ \\
\hline
\end{tabular}

Abbreviations: CKD, chronic kidney disease; GFR, glomerular filtration rate.

appeared to be independent predictors of cardiovascular events $(P=0.018) .{ }^{16}$

Similar findings were reported in the Korean Acute Myocardial Infarction Registry. In 11,462 patients with acute myocardial infarction, the 1-year mortality rate was higher in patients with both MetS and renal insufficiency than in those with MetS without renal insufficiency (HR 1.42; 95\% CI 1.03-1.95; $P=0.033$ ) or in individuals without MetS (HR 1.42; 95\% CI 1.03-1.95; $P=0.033$ and HR 1.08; $95 \%$ CI $0.77-1.51 ; P=0.677) .{ }^{17}$

Furthermore, insulin resistance in CKD patients is associated with increased arterial stiffness. ${ }^{18}$ The synergistic effect of decreased insulin sensitivity and CKD on mortality was demonstrated in a very recent study by $\mathrm{Xu}$ et al ${ }^{19}$ of 449 elderly men with stages 3-4 CKD, ages 70-71 years. After adjusting for confounders, glucose disposal rate (GDR) during euglycemic, hyperinsulinemic clamp was an independent correlate of all-cause mortality in smokers (adjusted HR $0.72 ; 95 \%$ CI $0.54-0.96$ per $1 \mathrm{mg} / \mathrm{kg}$ per minute increase in GDR) and physically inactive individuals (HR 0.77; 95\% CI $0.61-0.97$ ) but not their matched controls. In other words, the higher the GDR (greater insulin sensitivity), the lower the all-cause mortality. ${ }^{19}$

Finally, the development of MetS in 200 patients with stage 4 and 5 CKD was an independent predictor of time to composite end-point of cardiovascular death, acute coronary syndrome, revascularization, nonfatal stroke, and amputation (adjusted HR 2.46; 95\% CI 1.17-5.18). ${ }^{20}$

Awareness of this relationship and implementing interventions that reduce incident MetS and manage MetS-related risk factors when present may decrease incident cardiorenal disease in CKD patients.

\section{The link of MetS to CKD}

Individual components of the MetS are associated with the development of albuminuria and decreased GFR. For example, hypertension alone may lead to glomerulosclerosis 
and mild proteinuria independently from hyperlipidemia and central obesity. However, an increasing body of evidence in the last decade suggests that MetS has an additive risk on the development and the progression of CKD.

In this review, we will focus on the literature linking the MetS (defined by NCEP-ATPIII) as a cluster to renal dysfunction defined by either albuminuria, decreased GFR, or both (Table 3 ).

Chen et al analyzed data on 7,800 participants with MetS in the NHANES III who were followed for over 21 years. Individuals with the MetS were at 2.6-fold greater risk of incident CKD (defined as eGFR $<60 \mathrm{~mL} / \mathrm{min}$ ) than individuals without MetS. The risk of CKD increased with the number of MetS components from an odds ratio (OR) of 1.89 in adults with one MetS component to 5.85 in adults with all five components. The risk of microalbuminuria among adults with MetS was double that of adults without. The risk of microalbuminuria also increased in a step-wise fashion with the number of MetS components. ${ }^{21}$

In another analysis of the NHANES III data, incident microalbuminuria was greater in both women (OR 2.2; 95\% CI 1.44-3.34) and men (OR 4.1; 95\% CI 2.45-6.74) with MetS than without MetS. ${ }^{22}$

Similar findings were reported in the Atherosclerosis Risk in Communities Study. In this study, 10,096 nondiabetic subjects with normal baseline GFR were followed for 9 years. The risk of developing CKD was $43 \%$ higher in subjects with the MetS than those without (OR 1.43; 95\% CI 1.18-1.73). After adjusting for incident diabetes and hypertension, the risk of CKD remained higher in adults with MetS than without the MetS (OR 1.24; 95\% CI 1.01-1.51). ${ }^{23}$

Among 447 adults with untreated stage 1 and 2 essential hypertension, incident microalbuminuria was significantly greater in those with MetS than without the MetS after adjustment for systolic blood pressure. ${ }^{24}$ In a cohort of 353 individuals without $\mathrm{CKD}$, prevalent microalbuminuria was greater among patients with MetS than without the MetS (36.2\% versus $19.3 \% ; P<0.002) .{ }^{25}$

Other studies documented a close association between MetS and the development of CKD defined as decreased eGFR. In a cross-sectional study of 15,160 Chinese adults, Chen et al found that the multivariate-adjusted ORs (95\% CI) of CKD and elevated serum creatinine in participants with MetS compared to those without the MetS were 1.64 (1.16-2.32) and 1.36 (1.07-1.73), respectively. Compared to those without any components of the MetS, the multivariateadjusted ORs (95\% CI) of CKD were 1.51 (1.02-2.23), 1.50 (0.97-2.32), 2.13 (1.30-3.50), and 2.72 (1.50-4.93) for those with one, two, three, and four or five components, respectively. The corresponding multivariate-adjusted ORs (95\% CI) of elevated serum creatinine were $1.11(0.88-1.40)$, 1.39 (1.07-2.04), 1.47 (1.06-2.04), and 2.00 (1.32-3.03) respectively. ${ }^{26}$

The Strong Heart Study enrolled 1,484 Native Americans without diabetes between 1988 and 1999. The multivariable adjusted HR for CKD associated with MetS was 1.3 (95\% CI 1.1-1.6). Equivalent HRs for albumin-tocreatinine ratio greater than $30 \mathrm{mg} / \mathrm{g}$ and eGFR less than $60 \mathrm{~mL} / \mathrm{min} / 1.73 \mathrm{~m}^{2}$ were $1.4(95 \%$ CI 1.0-1.9) and $1.3(95 \%$ CI 1.0-1.6), respectively. The relationship between MetS and kidney outcomes was stronger in those who developed diabetes during follow-up. ${ }^{27}$ In a similar study of 118,924 individuals in China, Sun et al reported that MetS was predictive of CKD defined by incident proteinuria (HR 1.39; 95\% CI 1.24-1.36) and stage 3 or lower eGFR (1.37; 95\% CI 1.3-1.44). ${ }^{28}$

MetS predicted CKD in 6,980 Japanese adults participating in a screening program. There was a linear association between the number of MetS components and prevalent CKD (adjusted OR 1.54 and 95\% CI 1.287-1.85; $P<0.0001$ ). ${ }^{29}$

Similar results were found in the Korean population, in a retrospective study of 60,921 healthy adults; prevalence of CKD was greater in those with MetS $(11.0 \%$ versus $6.3 \% ; P<0.001)$ than those without MetS. This prevalence increased with the number of components of the MetS, and this association persisted after multivariate adjustment with OR was 1.680 (95\% CI 0.566-1.801). ${ }^{30}$

Surendar et al estimated GFR using cystatin C (cys-C) in a study of Indian Asians enrolled in the Chennai Urban Rural Epidemiology Study. Participants were divided according to the components of the MetS. Those with four or five metabolic abnormalities had the highest cys-C levels, and with a decreasing number of metabolic abnormalities, the cys- $\mathrm{C}$ levels decreased linearly ( $\mathrm{P}$ for trend $<0.001$ ). ${ }^{31}$

In another study from Asia, Yang et al followed 4,248 Chinese adults in Taiwan for a median of 5.40 years. The multivariate-adjusted HR of CKD in participants with MetS compared with those without was 1.42 (95\% CI 1.03-1.73). Additionally, there was a significantly graded relationship between the number of the MetS components and risk of CKD. ${ }^{32}$

Ninomiya et al analyzed the association between the GFR slope and MetS by using a multiple regression model. In this study, 1,440 individuals over the age of 40 years, without CKD, were followed for 5 years. The multivariate-adjusted mean value for the GFR slope decreased significantly faster in subjects with four or more MetS components in comparison 


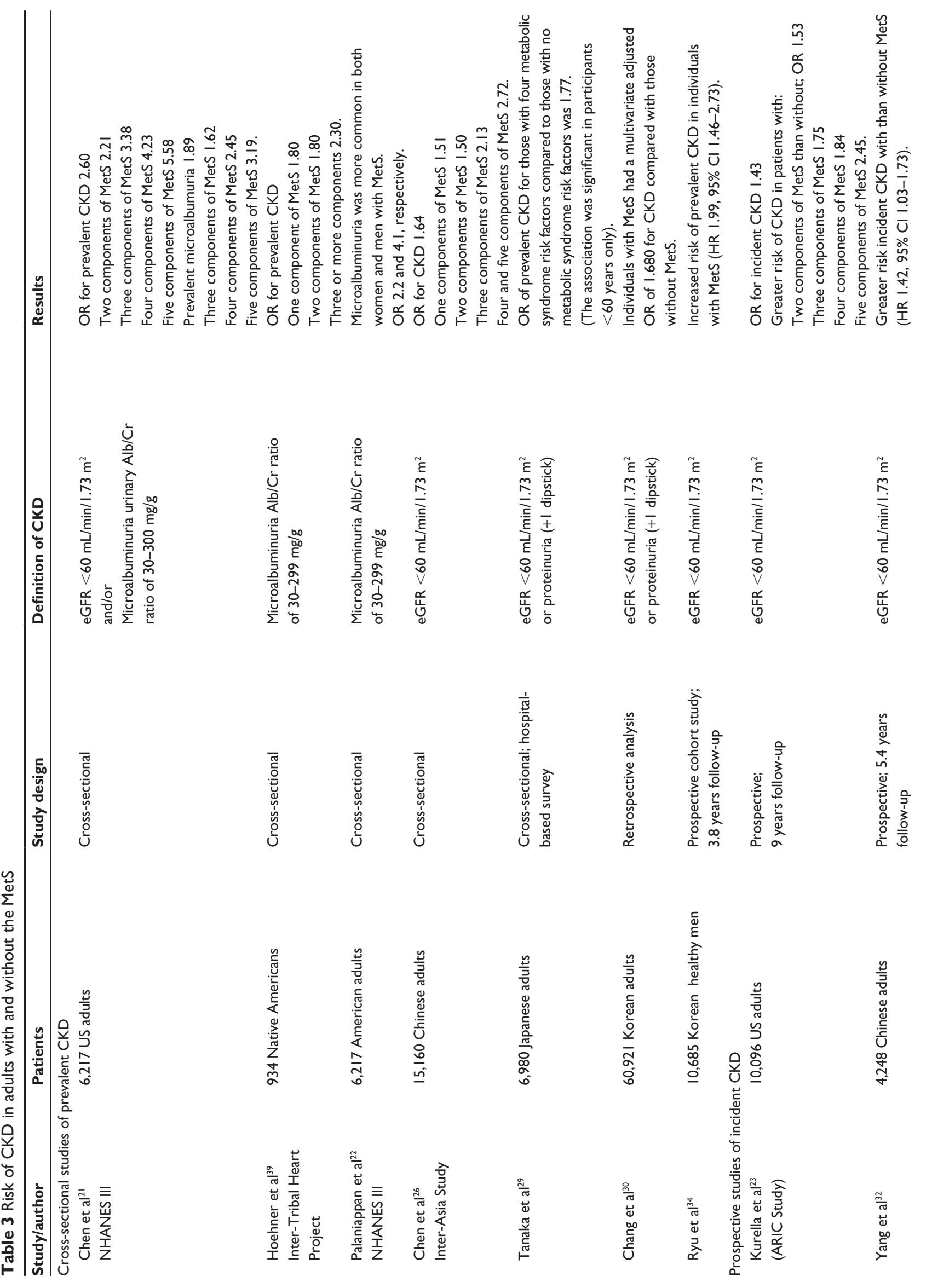



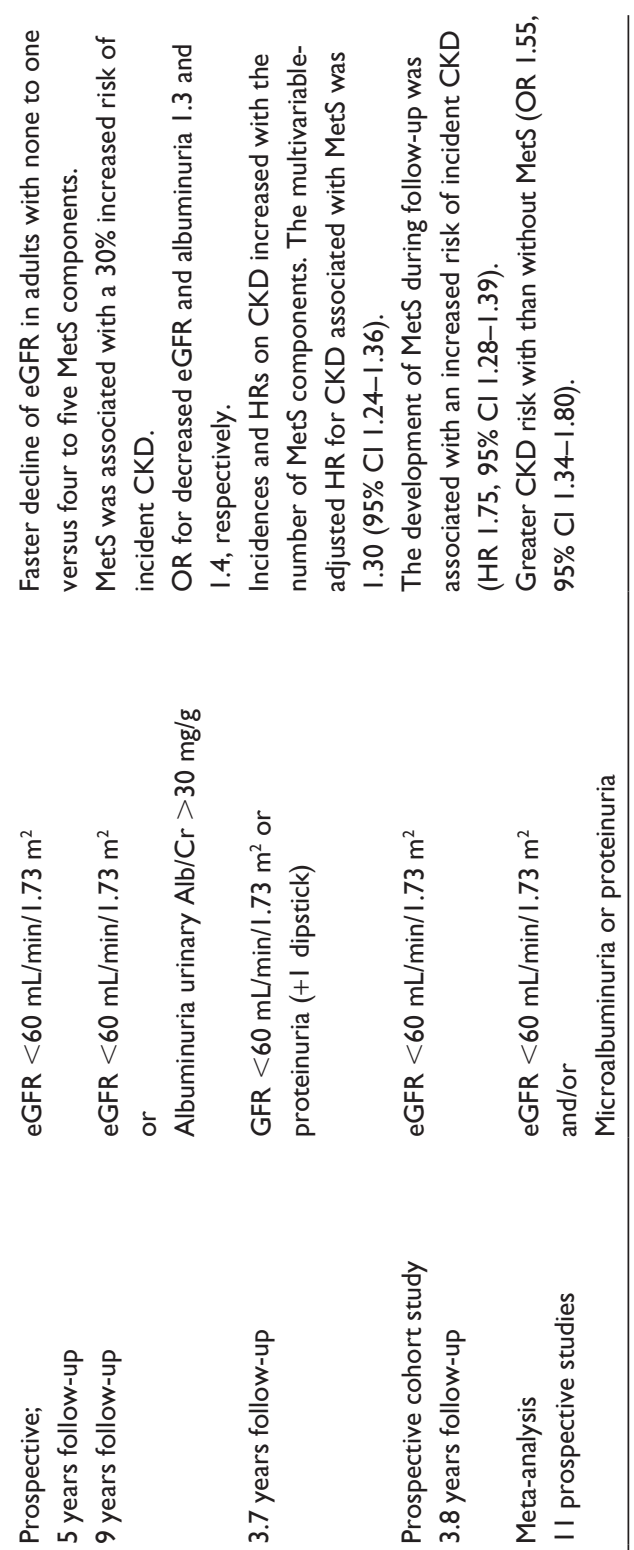

윽

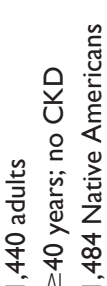

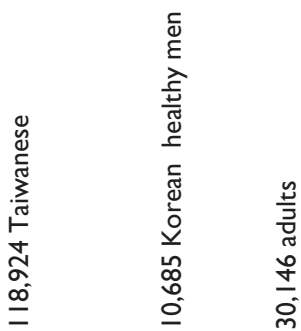

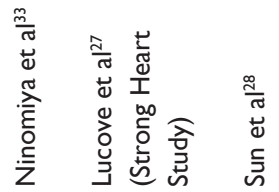

with those who had one or no components, and the mean of the GFR slope showed a significantly greater decline in subjects with three MetS components in the group 60 years and older. ${ }^{33}$

More evidence was provided in a prospective study of 10,685 Korean men who had no diabetes or hypertension and who were followed longitudinally over 3.8 years. It was found that individuals with preexisting MetS $(\mathrm{n}=787$ ) were at increased risk for CKD (HR, 1.99; 95\% CI 1.46-2.73). The development of MetS during follow-up was also associated with an increased risk of incident CKD (HR 1.75; 95\% CI 1.28-1.39). ${ }^{34}$

Thomas et al performed a meta-analysis that assessed the relationship between MetS and CKD in eleven prospective observational studies with 30,146 individuals. OR for the association of the MetS (using NCEP-ATPIII definition) and CKD (defined as eGFR $<60 \mathrm{~mL} / \mathrm{min}$ per $1.73 \mathrm{~m}^{2}$ ) was 1.55 (95\% CI 1.34-1.80). The strength of the association increased as the number of MetS components increased (trend $P$-value $=0.02$ ). ${ }^{35}$

In another prospective study, Rashidi et al reported an 88\% (OR 1.88, 1.26-2.8) increased risk for CKD in patients with MetS compared to those without, within a 3-year follow-up. In a multivariate analysis, hypertension was the strongest predictor of CKD among the components of the MetS (OR 3.4; 95\% CI 2.2-5.4; $P<0.001$ ). When patients with hypertension were excluded, the incidence of CKD after 3 years was not statistically significant (OR $0.925 ; 95 \%$ CI $0.446-1.917 ; P=0.844) .{ }^{36}$

The prospective studies in Table 3 demonstrate a clear epidemiological link between the MetS and incident kidney disease. Despite differences in the follow-up times, populations, and methodology, these studies agree on a close relationship between MetS and both prevalent and incident kidney disease.

The link between kidney disease and the MetS was further established by histopathology. Alexander et al retrospectively evaluated the records of 146 patients from the Brigham and Women's Hospital who underwent elective nephrectomy for renal cell carcinoma between 2005 and 2007. Twelve patients who met the NCEP-ATPIII definition of MetS were matched with twelve patients who did not have MetS. Pathologists were blinded to the clinical diagnosis of these patients. Compared with healthy controls, patients with MetS had higher prevalence of tubular atrophy $(P=0.0006)$, interstitial fibrosis $(P=0.001)$, and arterial sclerosis $(P=0.001)$. Patients with MetS had more global glomerulosclerosis and segmental glomerulosclerosis ( $P=0.04$ and $P=0.05$, respectively). 
Moreover, the eGFR 1 year after nephrectomy was significantly lower in patients with MetS than in controls (44.0 \pm 20 versus $\left.62.0 \pm 11 \mathrm{~mL} / \mathrm{min} / 1.73 \mathrm{~m}^{2} ; P=0.027\right) .{ }^{37}$

Several studies documented the presence of renal dysfunction prior to the onset of diabetes mellitus. Kohler et al conducted a cross-sectional analysis to describe the prevalence of and risk factors for microalbuminuria among blacks with newly diagnosed type 2 diabetes. Risk factors associated with increased albumin/creatinine included male sex, poor glycemic control, endogenous hyperinsulinemia, high blood pressure, elevated triglyceride levels, and obesity. ${ }^{38}$

\section{Insulin resistance and CKD}

While there is significant overlap between MetS and insulin resistance, the two terms are not synonymous. Several observational and prospective studies have suggested a relationship between insulin resistance and incident kidney disease (Table 4). ${ }^{39-43}$ In a cross-sectional survey of nondiabetic Native Americans enrolled in the Inter-Tribal Heart Project, insulin resistance was associated with twofold greater prevalence of microalbuminuria. OR for microalbuminuria was $1.8(95 \%$ CI 1.0-3.2) for two components and 2.3 (95\% CI 1.1-4.9) for three or more components versus no traits after controlling age, sex, smoking, body mass index (BMI), education, and family histories of diabetes and kidney disease. ${ }^{39}$

In an observational study of 133 middle-aged patients, hyperglycemia and insulin resistance in prediabetes stages was thought to be the main risk factor for renal dysfunction in diabetic patients. ${ }^{40}$

Chen et al demonstrated a step-wise increase in prevalent CKD as glucose tolerance decreased. In their study of 6,453 US adults without diabetes mellitus, the prevalence of CKD, defined as a GFR less than $60 \mathrm{~mL} / \mathrm{min}$, increased from $1.2 \%$ with fasting plasma glucose levels of $89-95 \mathrm{mg} / \mathrm{dL}$ to $4 \%$ with fasting glucose levels of at least $102 \mathrm{mg} / \mathrm{dL} .{ }^{41}$

In the Uppsala longitudinal study of adult men, glycemic clamps was employed to examine insulin sensitivity in $>1,000$ older community-dwelling men who were followed for over 7 years. This study showed a direct positive association between insulin sensitivity and eGFR (95\% CI 0.69-1.68; $P<0.001)$; this association was still significant after adjustment for age, glucometabolic and cardiovascular risk factors. Furthermore, in longitudinal analyses, higher insulin sensitivity at baseline was associated with lower risk of impaired renal function (GFR $<50 \mathrm{~mL} / \mathrm{min} / 1.73 \mathrm{~m}^{2}$ ) during follow-up, independently of glucometabolic variables (multivariable-adjusted OR for

Table 4 Studies that evaluated the association between insulin resistance and CKD

\begin{tabular}{|c|c|c|c|c|}
\hline Study/author & Patients & Study design & Definition of CKD & Results \\
\hline \multicolumn{5}{|c|}{ Cross-sectional studies of prevalent CKD } \\
\hline Hoehner et al ${ }^{39}$ & 934 Native Americans & Cross-sectional & $\begin{array}{l}\text { Microalbuminuria Alb/Cr } \\
\text { ratio of } 30-299 \mathrm{mg} / \mathrm{g}\end{array}$ & $\begin{array}{l}\text { OR for CKD } \\
\text { Two components of MetS, I.8 } \\
\text { Three or more components, } 2.3 \text {. }\end{array}$ \\
\hline Chen et $\mathrm{al}^{41}$ & $\begin{array}{l}6,453 \text { US adults without } \\
\text { diabetes }\end{array}$ & Cross-sectional & $\mathrm{eGFR}<60 \mathrm{~mL} / \mathrm{min} / 1.73 \mathrm{~m}^{2}$ & $\begin{array}{l}\text { OR of CKD } \\
\text { Serum insulin } 4.03(\mathrm{Cl} \text { I.8I-8.95; } P=0.00 \mathrm{I}) \\
\text { C-peptide II.4 }(\mathrm{Cl} 4.07-32 . \mathrm{I} ; P<0.00 \mathrm{I}) \\
\mathrm{HbA}{ }_{\mathrm{Ic}} 2.67(\mathrm{Cl} \text { I.3I-5.46; } P=0.002) \\
\text { HOMA-insulin resistance } 2.65 \\
(\mathrm{Cl} \text { I.25-5.62; } P=0.008) .\end{array}$ \\
\hline \multicolumn{5}{|c|}{ Prospective studies of incident CKD } \\
\hline Niskanen et al ${ }^{40}$ & I44 middle-aged adults & $\begin{array}{l}\text { Prospective observational } \\
\text { I0 years follow-up }\end{array}$ & $\begin{array}{l}\text { Microalbuminuria: urinary } \\
\text { albumin excretion of } \\
30-300 \mathrm{mg} / 24 \text { hour } \\
\text { Macroalbuminuria: } \\
>300 \mathrm{mg} / 24 \text { hour }\end{array}$ & $\begin{array}{l}\text { The development of both micro and } \\
\text { macroalbuminuria was strongly } \\
\text { associated with hyperglycemia and } \\
\text { fasting insulin levels (trend } P<0.00 \mathrm{I} \text { ). }\end{array}$ \\
\hline Nerpin et $\mathrm{al}^{42}$ & I,070 elderly men & $\begin{array}{l}\text { Prospective } \\
7 \text { years follow-up }\end{array}$ & $\begin{array}{l}\text { Cystatin C-based eGFR } \\
<50 \mathrm{~mL} / \mathrm{min} / 1.73 \mathrm{~m}^{2}\end{array}$ & $\begin{array}{l}\text { Higher insulin sensitivity at baseline } \\
\text { was associated with lower risk of } \\
\text { impaired renal function; OR for I-unit } \\
\text { higher of insulin sensitivity } 0.58 \\
([95 \% \mathrm{Cl} 0.40-0.84] ; P<0.004) \text {. }\end{array}$ \\
\hline Li et $\mathrm{al}^{43}$ & 2,696 Chinese adults & $\begin{array}{l}\text { Prospective } \\
7 \text { years follow-up }\end{array}$ & $\begin{array}{l}\text { Decline in renal function } \\
\text { defined as drop in } \\
\text { eGFR by } 25 \% \text { or } \\
>5 \mathrm{~mL} / \mathrm{min} / 1.73 \mathrm{~m}^{2} / \text { year }\end{array}$ & $\begin{array}{l}\text { Insulin resistance was NOT associated } \\
\text { with decline in renal function OR } 0.97 \\
(0.79-1.19) \text {. }\end{array}$ \\
\hline
\end{tabular}

Abbreviations: Alb, albumin; $\mathrm{Cl}$, confidence interval; $\mathrm{CKD}$, chronic kidney disease; $\mathrm{Cr}$, creatine; eGFR, estimated glomerular filtration rate; $\mathrm{HbA}_{\mathrm{lc}}$, hemoglobin $\mathrm{A}_{\mathrm{lc}}$; $\mathrm{HOMA}$, hemostasis model assessment; MetS, metabolic syndrome; OR, odds ratio. 
1-unit higher of the insulin sensitivity index (M/I) $0.58[95 \%$ CI $0.40-0.84] ; P<0.004) .{ }^{42}$

The effect of MetS versus insulin resistance on renal function was evaluated in a recent study of 2,696 Chinese adults. After a follow-up period of 7 years, subjects with MetS were found to be at an increased risk of renal function decline (defined by drop in eGFR by $25 \%$ or sustained decline in eGFR of more than $5 \mathrm{~mL} / \mathrm{min} / 1.73 \mathrm{~m}^{2} /$ year); OR 1.77 (95\% CI 1.25-2.52). However, insulin resistance at baseline (defined as $>$ the sex-specific percentiles of hemostasis model assessment [HOMA]-insulin resistance) was not associated with renal function decline; OR 0.97 $(0.79-1.19){ }^{43}$

In summary, fewer studies evaluated the relationship between insulin resistance and CKD, and methods to assess insulin resistance varied. The majority of studies pointed toward a possible link between insulin resistance and incident CKD.

\section{MetS and kidney disease: a bidirectional relationship?}

In this section, we will review the evidence linking CKD to the development of both insulin resistance and the MetS. Evidence from animal studies has shown that kidney failure led to hyperglycemia and hyperinsulinemia. ${ }^{44,45}$

In humans, the development of insulin resistance and hyperinsulinemia in patients with CKD was recognized decades ago ${ }^{46-48}$ DeFronzo et al were first to demonstrate this by assessing tissue sensitivity to insulin with the euglycemic insulin clamp technique in patients with renal insufficiency. ${ }^{49}$

Other observational studies showed that insulin resistance is present in mild kidney disease, irrespective of its etiology, and progresses as kidney function diminishes. Fliser et al demonstrated an association between insulin resistance and the degree of renal dysfunction in patients with polycystic kidney disease and immunoglobulin A nephropathy. ${ }^{50}$

Kato et al investigated insulin sensitivity in 18 young, lean nondiabetic male patients with biopsy-proven chronic glomerulonephritis. They found that GFR was notably lower in individuals with insulin resistance compared to those who were insulin sensitive $(P=0.0003)$; eGFR correlated significantly with insulin sensitivity $(r=0.58, P<0.02) .{ }^{51}$

Among 6,453 adults with diabetes in the NHANES III survey, Chen et al reported that prevalent CKD was significantly and progressively higher with increasing levels of serum insulin, C-peptide, hemoglobin $\mathrm{A}_{1 \mathrm{c}}$, and HOMA-insulin resistance. The OR of CKD for the highest compared with the lowest quartile was 4.03 (95\% CI 1.81-8.95; $P=0.001)$, 11.4 (95\% CI 4.07-32.1; $P<0.001$ ), 2.67 (95\% CI 1.31-5.46; $P=0.002)$, and 2.65 (95\% CI 1.25-5.62; $P=0.008)$ for serum insulin, C-peptide, hemoglobin $\mathrm{A}_{1 \mathrm{c}}$ levels, and HOMA-insulin resistance, respectively. ${ }^{40}$

In fact, insulin resistance increases progressively and linearly with declining renal function. In a study by Kobayashi et al, the hyperinsulinemic euglycemic glucose clamp technique was used to examine insulin sensitivity in 29 patients without diabetes but with different stages of renal function. It was found that insulin sensitivity was diminished in patients with CKD. The GDR of patients with CKD $(6.91 \pm 2.46 \mathrm{mg} / \mathrm{kg} / \mathrm{min})$ was significantly less than that of healthy subjects $(9.93 \pm 1.33 \mathrm{mg} / \mathrm{kg} / \mathrm{min} ; P<0.01)$. A negative correlation between GDR and serum creatinine level $(r=-0.449 ; P<0.05)$ and positive correlations between GDR and creatinine clearance $(r=0.549 ; P<0.01)$ and Apo A-1/B levels $(r=0.396 ; P<0.05)$ were noted. ${ }^{52}$

In a study of septuagenarians, stage $3 \mathrm{CKD}$ was associated with a $40 \%$ increased odds of insulin resistance and was associated with higher visceral fat mass. This was the first prospective study to evaluate whether kidney disease predicted the development or worsening of insulin resistance. ${ }^{53}$

The effect of insulin resistance on progression of CKD was evaluated in 1,456 elderly individuals from Taiwan. Using the HOMA formula, each unit increment of insulin resistance was associated with 1.16-fold increase in the HR $(95 \%$ CI $1.06-1.26 ; P<0.01)$ of decline in renal function. ${ }^{54}$

It appears that uremia-induced insulin resistance resolves at the initiation of renal replacement therapies. This may suggest the presence of dialyzable substances that mediate this process. ${ }^{55}$

Similarly to insulin resistance, the development of MetS in patients with CKD was demonstrated in prospective studies. In a study from Hungary, among 223 patients with immunoglobulin A nephropathy, MetS was diagnosed in 107 patients at the time of diagnosis or during follow-up. There was significant association between MetS and doubling serum creatinine in these patients 95\% CI 1.96 $(1.17-1.33 ; P=0.011)$. The association remained significant after adjustment for confounders: 1.70 (1.02-3.83; $P=0.040) .{ }^{56}$

Not only is MetS associated with incident CKD but also with its progression. In a single center study from Japan, MetS predicted a composite outcome of progression of CKD, ESRD and death in 213 Japanese subjects. In this study MetS was associated with higher urinary albumin-to-creatinine 
levels, and survival was significantly higher among individuals without MetS $(P=0.0086) .{ }^{57}$

\section{Mechanisms of the interrelationship between MetS and CKD}

The exact mechanism that links the MetS to renal damage has not yet been completely elucidated. The pathophysiological factors contributing to renal disease in patients with MetS are complex and include insulin resistance, adipocytokines, endothelial dysfunction, renin-angiotensin-aldosteronesystem (RAAS) activation, and oxidative stress.

\section{Oxidative stress}

The role of oxidative stress was documented in animal studies. In a study by Wang et al, 4-week old, obese Zucker rats were randomized into three groups: control, vehicle dimethyl sulfoxide, and acetaminophen treated. Lean Zucker rats were considered healthy controls. Tubulointerstitial fibrosis, inflammation, and atrophy were significantly more evident in the obese rats compared with the lean ones. Treatment with acetaminophen reduced markers of tubular injury, suggesting a role for oxidative stress via decreasing tissue superoxide and macromolecular oxidation. $^{58}$

Johnson et al reported that MetS in patients with advanced CKD correlated with oxidative stress and reduced adiponectin levels. ${ }^{20}$

\section{The role of inflammation}

The constellation of insulin resistance, hypertension, and inflammation releases inflammatory cytokines, including interleukin-6 and tumor necrosis factor-alpha, which cause renal fibrosis. ${ }^{59}$ The role/association of inflammation and CKD was implicated in a cross-sectional study by Lee et al, who studied the interrelationships between elevated C-reactive protein (defined as $>3$ ), MetS (NCEPATPIII definition), and CKD (eGFR $<60 \mathrm{~mL} / \mathrm{min} / 1.73 \mathrm{~m}^{2}$ or albuminuria) in 9,586 subjects without diabetes mellitus or hypertension. Subjects with high C-reactive protein and MetS had a greater likelihood of having CKD (OR 3.26; $95 \%$ CI 2.00-5.31). ${ }^{60}$

\section{The role of angiotensin II}

Visceral adipocytes secrete angiotensinogen and thus stimulate the renin-angiotensin-aldosterone pathway to cause hypertension, hyperfiltration, and renal injury ${ }^{61}$ Insulin resistance is associated with a more active RAAS. ${ }^{62}$ This may contribute to the enhanced oxidative stress vascular remodeling and pressor responses to exercise, a predictor of both cardiovascular and renal risk. ${ }^{63,64}$

Additionally, angiotensin II levels are considered to be potent activators of transforming growth factor $\beta 1$ (TGF- $\beta 1$ ) expression, a fibrogenic cytokine that contributes to glomerular injury. ${ }^{65}$

\section{The role of adipokines}

Adipose tissue is a highly active endocrine organ, secreting numerous factors that contribute to renal and cardiovascular complications. These factors regulate glucose and lipid metabolism. Leptin, a small peptide produced mainly in adipocytes of white fat tissue, is increased in patients with MetS. Leptin is cleared by the kidneys and has numerous effects on the kidney, which were summarized by Wolf et al. ${ }^{66}$ Leptin mediates sympathetic nerve activation, and infusion of leptin into rats increases renal sympathetic nervous activity. The role of sympathetic renal nerves in the development and course of hypertension has been proven in both animal experimental models and in human studies. ${ }^{67,68}$ Additionally, leptin stimulates the proliferation of cultured glomerular endothelial cells, increases TGF- $\beta 1$ synthesis in endothelial cells, and upregulates TGF- $\beta$ type II receptor expression. TGF- $\beta$ is a fibrogenic mediator in various renal diseases. Some authors suggest that leptin also may have profibrotic effects on mesangial cells, independent of the TGF- $\beta$ pathway. ${ }^{69}$ Finally, leptin was linked to increased production of oxidative stress in human endothelial cells. ${ }^{70}$ High levels of leptin after a nephrectomy may be responsible for the development of glomerulosclerosis in the remaining kidney. ${ }^{71}$

Similar to leptin, resistin is another adipokine which appears to participate in insulin resistance and kidney disease. Resistin is markedly increased in obese experimental animals, and its levels are lowered by thiazolidinediones (TZD). TZDs are drugs currently used to treat type 2 diabetes by increasing insulin sensitivity. TZDs also inhibit leptin production and ameliorate microalbuminuria, both in the streptozotocininduced diabetic rat and type 2 diabetic patients. ${ }^{72}$

Adiponectin is an adipokine that is synthesized and secreted by adipocytes. It is known to have strong anti-inflammatory and antiatherosclerotic properties. Deficiency of adiponectin plays an important pathophysiologic role in patients with impaired glucose homeostasis. ${ }^{73}$

Adiponectin deficiency is linked to the development of albuminuria in obese patients. This may help explain the link between obesity and kidney disease. In animal models, adiponectin knockout mice exhibited increased albuminuria and fusion of podocyte foot processes. In cultured podocytes, 
the infusion of adiponectin reduced podocyte permeability to albumin and podocyte dysfunction. The presumed mechanism is reduction of oxidative stress, as adiponectin regulated an isoform of NADPH oxidase through the ADP-activated protein kinase pathway. ${ }^{74}$

In a large prospective trial of patients with mild to moderate kidney disease, insulin resistance was associated with low adiponectin levels similar to what is found in patients with the MetS. ${ }^{75}$ In this prospective study, adiponectin levels were inversely related to cardiovascular events. Furthermore, in an earlier study of patients with advanced kidney disease, low adiponectin values were significantly related to cardiovascular events (HR 1.56; $95 \%$ CI $1.12-1.99) .^{76}$

\section{The role of overweight and obesity}

The link between obesity and CKD has been recognized for nearly a century. ${ }^{77}$ However, there is little published information on the relationship between renal dysfunction and total or regional body fat.

Perhaps one of the strongest epidemiological studies associating obesity (defined by BMI $>25 \mathrm{~kg} / \mathrm{m}^{2}$ ) and CKD comes from the Kaiser Permanente database. Hsu et al evaluated over 320,000 members of the Kaiser Permanente healthcare system who volunteered for screening and were followed for 15-35 years. The risk of ESRD increased in a step-wise fashion as BMI rose, even after adjusting for blood pressure, diabetes, smoking, and cardiovascular disease. $^{78}$

In a multivariate analysis of the NHANES III data, it was found that risk of prevalence for CKD was more than twice as high in patients with an increased waist circumference, suggesting that abdominal obesity may be an independent risk factor for CKD. ${ }^{21}$

In a cohort of 1,683 nondiabetic Chinese adults, insulin resistance, assessed by HOMA, was not associated with CKD $\left(\mathrm{eGFR}<60 \mathrm{~mL} / \mathrm{min} .1 .73 \mathrm{~m}^{2}\right)$ in those with normal weight $\left(\mathrm{BMI}<24 \mathrm{~kg} / \mathrm{m}^{2}\right.$ ) (relative risk 1.43, 95\% CI 0.87-2.36, $P=0.16$ ), comparing the highest to the lowest quartile of HOMA. However, HOMA was associated with prevalent decline in eGFR in the overweight/obese subpopulation ( $R$ 2.10, 95\% CI 1.11-3.97; $P=0.02) .{ }^{79}$ One can perhaps conclude that obese subjects are at increased risk of declining eGFR at levels of HOMA-insulin resistance that have no effect in lean individuals.

In another study, 8,792 healthy Korean men, who had no known risk factors for $\mathrm{CKD}$, were followed longitudinally. Weight gain greater than $0.75 \mathrm{~kg} /$ year was associated with a 3.74 higher HR for developing CKD compared to weight gain less than $0.75 \mathrm{~kg} /$ year. $^{80}$

Praga et al reported that obese patients are at high risk for developing proteinuria and CKD after unilateral nephrectomy. Among 14 obese patients with a BMI greater than $30 \mathrm{~kg} / \mathrm{m}^{2}, 13$ patients $(92 \%)$ developed proteinuria and renal insufficiency. Conversely, among 59 patients with a BMI less than $30 \mathrm{~kg} / \mathrm{m}^{2}$, only seven patients (12\%) developed these complications. ${ }^{81}$

The term "obesity-related glomerulopathy" (ORG) was first established by Kambham et al to describe a distinct histopathologic pattern characterized by glomerulomegaly with or without classical focal segmental glomerulosclerosis in obese patients $\left(\mathrm{BMI}>30 \mathrm{~kg} / \mathrm{m}^{2}\right)$. Compared with idiopathic focal segmental glomerulosclerosis, ORG has a lower incidence of nephrotic syndrome, more indolent course, consistent presence of glomerulomegaly, and milder foot process fusion. This was based on 6,818 native renal biopsies received from 1988-2000. During this period, a 10-fold increase in this biopsy diagnosis incidence was noted. This is alarming and consistent with the increase in the prevalence of obesity. ${ }^{82}$

Obesity is not only implicated in the development of CKD but also with a faster progression. Influence of obesity on progression of nondiabetic CKD was evaluated in a retrospective cohort study by Othman et al. One hundred twenty-five nondiabetic patients with stage $3 \mathrm{CKD}$ were followed at a single center for 10 years. Higher baseline BMI and younger age were strongly and independently associated with faster CKD progression (fall in eGFR $>1 \mathrm{~mL} / \mathrm{min} / 1.73 \mathrm{~m}^{2} /$ year) $\left(R^{2}=0.122 ; P<0.001\right){ }^{83}$

Obesity results in kidney disease beyond just CKD. In a meta-analysis examining the association between obesity and kidney disease, Wang et al reported $>60 \%$ increased risk for any kidney disease including nephrolithiasis, renal cancer, $\mathrm{CKD}$, and ESRD in BMI $>30 \mathrm{~kg} / \mathrm{m}^{2}$ (relative risk $=1.83$ $[1.57-2.13]) .^{84}$

The synergistic effect of obesity and hypertension on kidney function was examined by Munkhaugen et al who followed 74,986 adults participating in a Norwegian registry with a 20-year follow-up study. They found that prehypertension in nonobese patients was not a risk factor for incident kidney disease, whereas it was in obese patients. ${ }^{85}$

\section{Obesity: does it matter where the fat is?}

It is important to note that studies on obesity and outcomes did not always distinguish the fat distribution pattern. Abdominal obesity is considered the most important feature of the MetS. ${ }^{86}$ 
Abdominal obesity results from sedentary lifestyle and overeating. Additional genetic and environmental factors also play a role. Abdominal obesity results in insulin resistance. Visceral adipose tissue releases cytokines and free fatty acids responsible for insulin resistance. ${ }^{87,88}$ Abdominal fat can accumulate either subcutaneously or in the visceral compartments. It is not entirely proven which pattern is more predictive of insulin resistance; however, some studies have shown greater risk with visceral adiposity than abdominal subcutaneous fat. ${ }^{89,90}$ These considerations should be taken into account when investigating the clinical impact of MetS. ${ }^{87-90}$

\section{The role of hypertension}

Another component of MetS is hypertension. Hypertension alone is a known cause of CKD and proteinuria, typically $<500 \mathrm{mg} /$ day. In fact, hypertension is the second leading cause of ESRD. ${ }^{91}$

It is associated with an approximately 2- to 3-fold increased risk of microalbuminuria. The development of microalbuminuria in hypertension is perhaps related to increased intraglomerular pressure and resultant injury to the epithelial lining leading to leakage of albumin. ${ }^{92,93}$

In a study discussed earlier by Rashidi et al, ${ }^{35}$ controlling for hypertension eliminated the statistical association between MetS and renal disease. This study suggests that hypertension is the key player in the MetS renal disease association; however, these results need to be replicated before a conclusion is drawn.

\section{CKD and the MetS - which component of the MetS is the main culprit?}

Since every component of the MetS is a risk factor for the development and progression of CKD, it would be helpful to know which components of the MetS contribute the most to CKD. Epidemiologic studies have demonstrated greater risk for renal dysfunction with specific components of the MetS. For example, hypertension and fasting plasma glucose levels of $>110 \mathrm{mg} / \mathrm{dL}$ were associated with the greatest risk for microalbuminuria and low GFR in the NHANES III data. ${ }^{21}$

Mänttäri et al tested the hypothesis that hyperlipidemia might also add a greater risk for accelerated renal dysfunction in patients with hypertension. A total of 2,702 dyslipidemic, middle-aged men without kidney disease participating in the Helsinki Heart Study were studied. Subjects with an elevated ratio of low-density lipoprotein to HDL cholesterol $(>4.4)$ had a $20 \%$ faster decline in eGFR than those with a ratio less than 3.2. ${ }^{94}$
In the Atherosclerosis Risk in Communities Study, reduced HDL cholesterol or elevated triglycerides levels were independently associated with a significantly increased risk for CKD (defined by increase serum creatinine $>0.4 \mathrm{mg} / \mathrm{dL}$ ) The adjusted relative risk for the highest versus lowest quartile of triglycerides was 1.65 (95\% CI 1.1-2.5; $P=0.01)$ and for HDL was 0.47 (95\% CI 0.3-0.8; $P=0.003) .{ }^{95}$

Observations in the Modification of Diet in Renal Disease Study cohort indicated that low levels of high-density lipoprotein HDL cholesterol predicts faster CKD progression in 840 patients with diverse renal diseases. ${ }^{96}$

To the contrary, data from 2,141 patients with diabetes mellitus and CKD stages 3-5 enrolled in the Kidney Early Evaluation Program showed that overall glycemic control but not lipids were associated with abnormal urinary albumin excretion, a marker of increased risk for progressive disease. ${ }^{97}$ In summary, it is not entirely clear whether one component of the MetS has more significance than the others in the development of CKD.

\section{Potential therapeutic interventions}

Well-designed studies that aim at evaluating potential interventions to improve renal outcomes in patients with MetS are lacking. Available studies are often small and short term or post hoc analyses of large trials. Furthermore, many studies do not evaluate hard renal outcomes like progression to ESRD. $^{98}$

There is no doubt that controlling the metabolic abnormalities in the MetS is important to cardiovascular disease prevention. ${ }^{99}$ It is well established that controlling these abnormalities delays renal disease in patients with diabetes; however, clinical trials in patients with the MetS are scarce. ${ }^{100}$ This is partially due to the fact that the mechanism of renal injury in MetS is not fully understood. Table 5 summarizes potential interventions from clinical trials.

Increased physical activity improves cardiovascular outcomes in patients with MetS. Although no prospective studies were undertaken on the effect of increased physical activity on renal function in individuals with the MetS, its positive effects on glucose and lipids metabolism, reduced inflammation, and improved endothelial function are well established. ${ }^{101}$

In a cross-sectional study, Finkelstein et al ${ }^{102}$ evaluated data from NHANES III and found a clear association between physical activity and eGFR. However, conclusion on causality could not be drawn given the nature of the study.

Several studies found that weight loss achieved by surgical and medical therapies resulted in decreased proteinuria 
Table 5 Summary of potential interventions in MetS and CKD

\begin{tabular}{ll}
\hline Intervention & Effect(s) \\
\hline Physical activity & Improves glucose and lipids \\
& metabolism Reduces inflammation \\
Improves endothelial function & Decreases proteinuria \\
Weight loss & Increases GFR in obese patients \\
& Delays progression to ESRD in \\
& CKD patients \\
Blood pressure control & Decreases the risk of CKD \\
$<$ I40/90 mmHg & progression \\
Sibutramine & Reduces risk of cardiovascular events \\
& Decreased Cystatin C but not \\
creatinine in clinical trials of obese & women with polycystic ovaries \\
Increases blood pressure \\
inhibitors & No effect on renal function in \\
\hline clinical trials
\end{tabular}

Abbreviations: CKD, chronic kidney disease; CoA, coenzyme A; ESRD, end stage renal disease; GFR, glomerular filtration rate; HMG-CoA, 3-hydroxy-3-methylglutaryl-CoA; MetS, metabolic syndrome; RAAS, renin-angiotensin-aldosterone system.

and improved GFR in obese patients. ${ }^{103}$ Chagnac et al ${ }^{104}$ found that weight loss ameliorates obesity-related glomerular hyperfiltration. The improvement in hyperfiltration may prevent the development of overt ORG.

Weight loss may be beneficial in delaying the progression of CKD to ESRD, but it is not indicated once renal replacement therapies are started. This is due to the paradoxical effect renal replacement therapies have on survival. ${ }^{105}$

The effect of several obesity drugs on renal function was evaluated in clinical trials. Sibutramine, a serotoninnorepinephrine reuptake inhibitor, which acts on the hypothalamic satiety center to reduce hunger, was used along with lifestyle modification for 6 months to reduce weight in obese women with polycystic ovary syndrome. The intervention resulted in weight loss and reduction in serum cys-C levels but not creatinine. It should be noted that sibutramine can raise blood pressure. ${ }^{106}$ Orlistat showed no improvement in renal function assessed by serum creatinine after 3 months of use. ${ }^{107}$

The role of RAAS inhibition is well established in delaying the progression of renal disease in diabetics (75\% have MetS). However, studies of RAAS inhibition and progression of renal disease have not been done specifically in MetS patients. Nonetheless, their antiproteinuric effect is well established. In a mouse model of obesity, olmesartan, an angiotensin II type 1 receptor blocker, significantly reduced inflammatory cytokines and markers of oxidative stress and increased adiponectin levels. ${ }^{108}$

Statins decrease proteinuria in renal disease. A metaanalysis of clinical trials indicates that lipid lowering preserves GFR and decreases proteinuria level in patients with renal disease. ${ }^{109}$

The management of lipid disorders was addressed in the 2014 KDIGO guidelines. The guidelines state that monitoring of lipid profiles might improve the health of people with secondary dyslipidemia and CKD. At the same time, it was acknowledged that no direct evidence indicates that following the recommendations will lead to better outcomes. The guidelines recommend that patients $\geq 50$ years of age with an eGFR $<60 \mathrm{~mL} / \mathrm{min} / 1.73 \mathrm{~m}^{2}$ not on dialysis receive a statin or statin/ezetimibe combination. Those with a higher eGFR should receive a statin. ${ }^{110}$

However, it remains unknown whether statin therapy is also effective in the prevention of the onset of renal dysfunction in patients with normal kidney function.

\section{Discussion}

In this review, cross-sectional studies show a close association of the MetS and CKD. The strength of association between MetS and CKD increased as the number of components increased from one to five. However, one cannot draw a conclusion as to which came first - the MetS or the kidney disease.

One of the challenges in this analysis is the multiple definitions for the MetS. In fact, a study of Kitiyakara et $\mathrm{al}^{111}$ has even suggested that the risk of CKD associated with the MetS was different depending on the definition of MetS used.

The components of the MetS individually are risk factors for cardiorenal disease; however, it remains unclear how much additive risk the clustering of these components contributes to the risk of individual traits. Clinical studies disagree on which combination of MetS components is more predictive of CKD. ${ }^{111}$ This uncertainty probably accounts for skepticism among some nephrologists on the significance of clustering of the MetS over the individual components in the pathogenesis of kidney disease. The dichotomization of continuous MetS variables may contribute to attenuation of predictive power. ${ }^{12}$

Similarly to cross-sectional studies, observational studies suggest a relationship of MetS with incident CKD. They also demonstrate the development of MetS in patients with established CKD, which suggests a bidirectional causal relationship between CKD and MetS. Regardless 


\section{Table 6 Clinical summary}

I. CKD is associated with MetS and its individual components in cross sectional studies.

2. Incident CKD is associated with MetS and vice versa, which suggests a bidirectional relationship.

3. An improved understanding of the pathogenesis of this relationship is needed to design clinical trials aiming toward therapeutic interventions.

Abbreviations: CKD, chronic kidney disease; MetS, metabolic syndrome.

of which comes first, both the MetS and CKD are strongly associated with cardiovascular and overall morbidity and mortality (Table 6).

The implications of CKD in patients with the MetS were significant enough to lead some investigators to propose including CKD in the definition of MetS. ${ }^{113}$ On the other hand, other authors suggest that perhaps the MetS is a marker and not a causative factor in the development of CKD. ${ }^{114}$

The relationship between MetS and CKD is complex. In order to assess renal outcomes in MetS, more studies on the mechanism of linkage are needed. Treating hypertension and hyperglycemia reduce kidney disease, as does treating lipids with statins. However, large randomized controlled trials of therapeutic regimens designed to prevent the onset and progression of cardiorenal disease in MetS are critical. Moreover, validated CKD risk score in patients with MetS similar to other scores used to stratify cardiovascular disease risk need to be formulated. ${ }^{108}$

Understanding the genetic and environmental factors that impact the relationship between CKD and MetS is also important. The clinical effects of MetS vary among ethnic groups. Race and sex affect the calculations used to estimate GFR. Lea et al ${ }^{115}$ outlined ethnic differences in the association between MetS and renal disease. In African Americans, MetS was not independently associated with CKD progression but was associated with proteinuria, suggesting the later as a confounding variable to explain the renal damage in MetS.

While awaiting further studies, awareness of the association between MetS and CKD is important. This awareness should prompt early implementation of lifestyle changes and aggressive control of blood pressure and lipids, which may improve cardiovascular outcomes.

\section{Disclosure}

The authors report no conflicts of interest in this work.

\section{References}

1. Kylin E. [Studies of the hypertension-hyperglycemia-hyperuricemia syndrome]. Zentralbl Inn Med. 1923;44:105-127. German.

2. Herman JB, Medalie JH, Goldbourt U. Diabetes, prediabetes and uricaemia. Diabetologia. 1976;12(1):47-52.
3. Reaven GM. Banting Lecture 1988. Role of insulin resistance in human disease. Diabetes. 1988;37(12):1595-1607.

4. Third Report of the National Cholesterol Education Program (NCEP) Expert Panel on Detection, Evaluation, and Treatment of High Blood Cholesterol in Adults (Adult Treatment Panel III) final report. Circulation. 2002;106(25):3143-3421.

5. Obunai K, Jani S, Dangas GD. Cardiovascular morbidity and mortality of the metabolic syndrome. Med Clin North Am. 2007;91(6): 1169-1184, x.

6. Caterson ID, Hubbard V, Bray GA, et al; American Heart Association. Prevention Conference VII: Obesity, a worldwide epidemic related to heart disease and stroke: Group III: worldwide comorbidities of obesity. Circulation. 2004;110(18):e476-e483.

7. Ford ES, Giles WH, Dietz WH. Prevalence of the metabolic syndrome among US adults: findings from the third National Health and Nutrition Examination Survey. JAMA. 2002;287(3):356-359.

8. Athyros VG, Ganotakis ES, Tziomalos K, et al. Comparison of four definitions of the metabolic syndrome in a Greek (Mediterranean) population. Curr Med Res Opin. 2010;26(3):713-719.

9. Kidney Disease: Improving Gobal Outcomes (KDIGO) CKD Work Group. KDIGO 2012 clinical practice guideline for the evaluation and management of chronic kidney disease. Kidney Int Supp. 2013;3(1):1-150.

10. Go AS, Chertow GM, Fan D, McCulloch CE, Hsu CY. Chronic kidney disease and the risks of death, cardiovascular events, and hospitalization. N Engl J Med. 2004;351(13):1296-1305.

11. Tonelli M, Wiebe N, Culleton B, et al. Chronic kidney disease and mortality risk: a systematic review. $J$ Am Soc Nephrol. 2006;17(7): 2034-2047.

12. Mottillo S, Filion KB, Genest J, et al. The metabolic syndrome and cardiovascular risk a systematic review and meta-analysis. $\mathrm{J} \mathrm{Am} \mathrm{Coll}$ Cardiol. 2010;56(14):1113-1132.

13. Li W, Ma D, Liu M, et al. Association between metabolic syndrome and risk of stroke: a meta-analysis of cohort studies. Cerebrovasc Dis. 2008;25(6):539-547.

14. Wu SH, Hui WS, Liu Z, Ho SC. Metabolic syndrome and all-cause mortality: a meta-analysis of prospective cohort studies. Eur $J$ Epidemiol. 2010;25(6):375-384.

15. Agrawal S, Shlipak MG, Kramer H, Jain A, Herrington DM. The association of chronic kidney disease and metabolic syndrome with incident cardiovascular events: multiethnic study of atherosclerosis. Cardiol Res Pract. 2012;2012:806102.

16. Kunimura A, Amano T, Uetani T, et al. Prognostic impact of concurrence of metabolic syndrome and chronic kidney disease in patients undergoing coronary intervention: involvement of coronary plaque composition. J Cardiol. 2013;61(3):189-195.

17. Kim CS, Choi JS, Bae EH, et al; Korea Acute Myocardial Infarction Registry Investigators. Association of metabolic syndrome and renal insufficiency with clinical outcome in acute myocardial infarction. Metabolism. 2013;62(5):669-676.

18. Chan DT, Watts GF, Irish AB, Ooi EM, Dogra GK. Insulin resistance and the metabolic syndrome are associated with arterial stiffness in patients with chronic kidney disease. Am J Hypertens. 2013;26(9):1155-1161.

19. Xu H, Huang X, Arnlöv J, et al. Clinical correlates of insulin sensitivity and its association with mortality among men with CKD stages 3 and 4 . Clin J Am Soc Nephrol. 2014;9(4):690-697.

20. Johnson DW, Armstrong K, Campbell SB, et al. Metabolic syndrome in severe chronic kidney disease: prevalence, predictors, prognostic significance and effects of risk factor modification. Nephrology (Carlton). 2007;12(4):391-398.

21. Chen J, Muntner P, Hamm LL, et al. The metabolic syndrome and chronic kidney disease in US adults. Ann Intern Med. 2004;140(3): 167-174.

22. Palaniappan L, Carnethon M, Fortmann SP. Association between microalbuminuria and the metabolic syndrome: NHANES III. Am J Hypertens. 2003;16(11 Pt 1):952-958. 
23. Kurella M, Lo JC, Chertow GM. Metabolic syndrome and the risk for chronic kidney disease among nondiabetic adults. J Am Soc Nephrol. 2005;16(7):2134-2140.

24. Cuspidi C, Meani S, Fusi V, et al. Metabolic syndrome and target organ damage in untreated essential hypertensives. J Hypertens. 2004;22(10):1991-1998.

25. Mulè G, Nardi E, Cottone S, et al. Influence of metabolic syndrome on hypertension-related target organ damage. J Intern Med. 2005;257(6): 503-513.

26. Chen J, Gu D, Chen CS, et al. Association between the metabolic syndrome and chronic kidney disease in Chinese adults. Nephrol Dial Transplant. 2007;22(4):1100-1106.

27. Lucove J, Vupputuri S, Heiss G, North K, Russell M. Metabolic syndrome and the development of CKD in American Indians: the Strong Heart Study. Am J Kidney Dis. 2008;51(1):21-28.

28. Sun F, Tao Q, Zhan S. Metabolic syndrome and the development of chronic kidney disease among 118924 non-diabetic Taiwanese in a retrospective cohort. Nephrology (Carlton). 2010;15(1):84-92.

29. Tanaka H, Shiohira Y, Uezu Y, Higa A, Iseki K. Metabolic syndrome and chronic kidney disease in Okinawa, Japan. Kidney Int. 2006;69(2):369-374.

30. Chang IH, Han JH, Myung SC, et al. Association between metabolic syndrome and chronic kidney disease in the Korean population. Nephrology (Carlton). 2009;14(3):321-326.

31. Surendar J, Indulekha K, Aravindhan V, Ganesan A, Mohan V. Association of cystatin-C with metabolic syndrome in normal glucosetolerant subjects (CURES-97). Diabetes Technol Ther. 2010;12(11): 907-912.

32. Yang $\mathrm{T}$, Chu $\mathrm{CH}$, Hsu $\mathrm{CH}$, et al. Impact of metabolic syndrome on the incidence of chronic kidney disease: a Chinese cohort study. Nephrology (Carlton). 2012;17(6):532-538.

33. Ninomiya T, Kiyohara Y, Kubo M, et al. Metabolic syndrome and CKD in a general Japanese population: the Hisayama Study. Am J Kidney Dis. 2006;48(3):383-391.

34. Ryu S, Chang Y, Woo HY, et al. Time-dependent association between metabolic syndrome and risk of CKD in Korean men without hypertension or diabetes. Am J Kidney Dis. 2009;53(1):59-69.

35. Thomas G, Sehgal AR, Kashyap SR, Srinivas TR, Kirwan JP, Navaneethan SD. Metabolic syndrome and kidney disease: a systematic review and meta-analysis. Clin J Am Soc Nephrol. 2011;6(10): 2364-2373.

36. Rashidi A, Ghanbarian A, Azizi F. Are patients who have metabolic syndrome without diabetes at risk for developing chronic kidney disease? Evidence based on data from a large cohort screening population. Clin J Am Soc Nephrol. 2007;2(5):976-983.

37. Alexander MP, Patel TV, Farag YM, Florez A, Rennke HG, Singh AK Kidney pathological changes in metabolic syndrome: a cross-sectional study. Am J Kidney Dis. 2009;53(5):751-759.

38. Kohler KA, McClellan WM, Ziemer DC, Kleinbaum DG, Boring JR. Risk factors for microalbuminuria in black Americans with newly diagnosed type 2 diabetes. Am J Kidney Dis. 2000;36(5):903-913.

39. Hoehner CM, Greenlund KJ, Rith-Najarian S, Casper ML, McClellan WM. Association of the insulin resistance syndrome and microalbuminuria among nondiabetic native Americans. The Inter-Tribal Heart Project. J Am Soc Nephrol. 2002;13(6):1626-1634.

40. Niskanen LK, Penttilã I, Parviainen M, Uusitupa MI. Evolution, risk factors, and prognostic implications of albuminuria in NIDDM. Diabetes Care. 1996;19(5):486-493.

41. Chen J, Muntner P, Hamm LL, et al. Insulin resistance and risk of chronic kidney disease in nondiabetic US adults. J Am Soc Nephrol. 2003;14(2):469-477.

42. Nerpin E, Risérus U, Ingelsson E, et al. Insulin sensitivity measured with euglycemic clamp is independently associated with glomerular filtration rate in a community-based cohort. Diabetes Care. 2008;31(8): 1550-1555.

43. Li Y, Xie D, Qin X, et al. Metabolic syndrome, but not insulin resistance, is associated with an increased risk of renal function decline. Clin Nutr. Epub April 16, 2014.
44. Aksentijević D, Bhandari S, Seymour AM. Insulin resistance and altered glucose transporter 4 expression in experimental uremia. Kidney Int. 2009;75(7):711-718.

45. Sun DF, Chen Y, Rabkin R. Work-induced changes in skeletal muscle IGF-1 and myostatin gene expression in uremia. Kidney Int. 2006;70(3):453-459.

46. Ma KW, Greene EL, Raij L. Cardiovascular risk factors in chronic renal failure and hemodialysis populations. Am J Kidney Dis. 1992;19(6):505-513.

47. Feneberg R, Sparber M, Veldhuis JD, Mehls O, Ritz E, Schaefer F. Altered temporal organization of plasma insulin oscillations in chronic renal failure. J Clin Endocrinol Metab. 2002;87(5):1965-1973.

48. Hager SR. Insulin resistance of uremia. Am J Kidney Dis. 1989; 14(4):272-276.

49. DeFronzo RA, Alvestrand A, Smith D, Hendler R, Hendler E, Wahren J. Insulin resistance in uremia. $J$ Clin Invest. 1981;67(2):563-568.

50. Fliser D, Pacini G, Engelleiter R, et al. Insulin resistance and hyperinsulinemia are already present in patients with incipient renal disease. Kidney Int. 1998;53(5):1343-1347.

51. Kato Y, Hayashi M, Ohno Y, Suzawa T, Sasaki T, Saruta T. Mild renal dysfunction is associated with insulin resistance in chronic glomerulonephritis. Clin Nephrol. 2000;54(5):366-373.

52. Kobayashi S, Maesato K, Moriya H, Ohtake T, Ikeda T. Insulin resistance in patients with chronic kidney disease. Am J Kidney Dis. 2005;45(2):275-280.

53. Landau M, Kurella-Tamura M, Shlipak MG, et al; Health, Aging and Body Composition Study. Correlates of insulin resistance in older individuals with and without kidney disease. Nephrol Dial Transplant. 2011;26(9):2814-2819.

54. Cheng HT, Huang JW, Chiang CK, Yen CJ, Hung KY, Wu KD. Metabolic syndrome and insulin resistance as risk factors for development of chronic kidney disease and rapid decline in renal function in elderly. J Clin Endocrinol Metab. 2012;97(4):1268-1276.

55. Kobayashi S, Maejima S, Ikeda T, Nagase M. Impact of dialysis therapy on insulin resistance in end-stage renal disease: comparison of haemodialysis and continuous ambulatory peritoneal dialysis. Nephrol Dial Transplant. 2000;15(1):65-70.

56. Kovács T, Vas T, Kovesdy C, et al. Metabolic syndrome and other cardiovascular risk factors associated with the progression of $\operatorname{IgA}$ nephropathy. Clin Kidney J. 2012;0:1-7.

57. Saito T, Mochizuki T, Uchida K, Tsuchiya K, Nitta K. Metabolic syndrome and risk of progression of chronic kidney disease: a single-center cohort study in Japan. Heart Vessels. 2013;28(3):323-329.

58. Wang C, Blough ER, Arvapalli R, et al. Metabolic syndromeinduced tubulointerstitial injury: role of oxidative stress and preventive effects of acetaminophen. Free Radic Biol Med. 2013;65: $1417-1426$

59. Wisse BE. The inflammatory syndrome: the role of adipose tissue cytokines in metabolic disorders linked to obesity. J Am Soc Nephrol. 2004;15(11):2792-2800.

60. Lee JE, Choi SY, Huh W, Kim YG, Kim DJ, Oh HY. Metabolic syndrome, C-reactive protein, and chronic kidney disease in nondiabetic, nonhypertensive adults. Am J Hypertens. 2007;20(11): 1189-1194.

61. Wajchenberg BL. Subcutaneous and visceral adipose tissue: their relation to the metabolic syndrome. Endocr Rev. 2000;21(6): 697-738.

62. Manrique C, Lastra G, Gardner M, Sowers JR. The renin angiotensin aldosterone system in hypertension: roles of insulin resistance and oxidative stress. Med Clin North Am. 2009;93(3):569-582.

63. Nashar K, Nguyen JP, Jesri A, Morrow JD, Egan BM. Angiotensin receptor blockade improves arterial distensibility and reduces exercise-induced pressor responses in obese hypertensive patients with the metabolic syndrome. Am J Hypertens. 2004;17(6): 477-482.

64. Taal MW. Arterial stiffness in chronic kidney disease: an update Curr Opin Nephrol Hypertens. 2014;23(2):169-173. 
65. Nitta K. Possible link between metabolic syndrome and chronic kidney disease in the development of cardiovascular cisease. Cardiol Res Pract. 2011;2011:963517.

66. Wolf G, Chen S, Han DC, Ziyadeh FN. Leptin and renal disease. Am J Kidney Dis. 2002;39(1):1-11.

67. Kirchheim H, Ehmke H, Persson P. Sympathetic modulation of renal hemodynamics, renin release and sodium excretion. Klin Wochenschr. 1989;67(17):858-864.

68. Kon V. Neural control of renal circulation. Miner Electrolyte Metab. 1989;15(1-2):33-43.

69. Wolf G, Hamann A, Han DC, et al. Leptin stimulates proliferation and TGF-beta expression in renal glomerular endothelial cells: potential role in glomerulosclerosis [see comments]. Kidney Int. 1999;56(3):860-872.

70. Kim HJ, Vaziri ND, Norris K, An WS, Quiroz Y, Rodriguez-Iturbe B. High-calorie diet with moderate protein restriction prevents cachexia and ameliorates oxidative stress, inflammation and proteinuria in experimental chronic kidney disease. Clin Exp Nephrol. 2010;14(6):536-547.

71. Praga M. Obesity - a neglected culprit in renal disease. Nephrol Dial Transplant. 2002;17(7):1157-1159.

72. Steppan CM, Bailey ST, Bhat S, et al. The hormone resistin links obesity to diabetes. Nature. 2001;409(6818):307-312.

73. Goldstein BJ, Scalia R. Adiponectin: a novel adipokine linking adipocytes and vascular function. J Clin Endocrinol Metab. 2004;89(6): 2563-2568.

74. Sharma K, Ramachandrarao S, Qiu G, et al. Adiponectin regulates albuminuria and podocyte function in mice. J Clin Invest. 2008;118(5): 1645-1656.

75. Becker B, Kronenberg F, Kielstein JT, et al; MMKD Study Group. Renal insulin resistance syndrome, adiponectin and cardiovascular events in patients with kidney disease: the mild and moderate kidney disease study. J Am Soc Nephrol. 2005;16(4):1091-1098.

76. Zoccali C, Mallamaci F, Tripepi G, et al. Adiponectin, metabolic risk factors, and cardiovascular events among patients with end-stage renal disease. J Am Soc Nephrol. 2002;13(1):134-141.

77. Preble WE. Obesity: observations on one thousand cases. Boston Med Surg J. 1923;188:617-621.

78. Hsu CY, McCulloch CE, Iribarren C, Darbinian J, Go AS. Body mass index and risk for end-stage renal disease. Ann Intern Med. 2006;144(1):21-28.

79. Chen S, Chen Y, Liu X, et al. Association of insulin resistance with chronic kidney disease in non-diabetic subjects with normal weight. PLoS One. 2013;8(9):e74058

80. Ryu S, Chang Y, Woo HY, et al. Changes in body weight predict CKD in healthy men. J Am Soc Nephrol. 2008;19(9):1798-1805.

81. Praga M, Hernández E, Herrero JC, et al. Influence of obesity on the appearance of proteinuria and renal insufficiency after unilateral nephrectomy. Kidney Int. 2000;58(5):2111-2118.

82. Kambham N, Markowitz GS, Valeri AM, Lin J, D’Agati VD. Obesity-related glomerulopathy: an emerging epidemic. Kidney Int. 2001;59(4):1498-1509.

83. Othman M, Kawar B, El Nahas AM. Influence of obesity on progression of non-diabetic chronic kidney disease: a retrospective cohort study. Nephron Clin Pract. 2009;113(1):c16-c23.

84. Wang Y, Chen X, Song Y, Caballero B, Cheskin LJ. Association between obesity and kidney disease: a systematic review and meta-analysis. Kidney Int. 2008;73(1):19-33.

85. Munkhaugen J, Lydersen S, Widerøe TE, Hallan S. Prehypertension, obesity, and risk of kidney disease: 20-year follow-up of the HUNT I study in Norway. Am J Kidney Dis. 2009;54(4):638-646.

86. Alberti KG, Zimmet P, Shaw J; IDF Epidemiology Task Force Consensus Group. The metabolic syndrome - a new worldwide definition. Lancet. 2005;366(9491):1059-1062.

87. Ross R, Freeman J, Hudson R, Janssen I. Abdominal obesity, muscle composition, and insulin resistance in premenopausal women. J Clin Endocrinol Metab. 2002;87(11):5044-5051.
88. Wagenknecht LE, Langefeld CD, Scherzinger AL, et al. Insulin sensitivity, insulin secretion, and abdominal fat: the Insulin Resistance Atherosclerosis Study (IRAS) Family Study. Diabetes. 2003;52(10):2490-2496.

89. Abate N, Garg A, Peshock RM, Stray-Gundersen J, Grundy SM. Relationships of generalized and regional adiposity to insulin sensitivity in men. J Clin Invest. 1995;96(1):88-98.

90. Goodpaster BH, Thaete FL, Simoneau JA, Kelley DE. Subcutaneous abdominal fat and thigh muscle composition predict insulin sensitivity independently of visceral fat. Diabetes. 1997;46(10): 1579-1585.

91. Klag MJ, Whelton PK, Randall BL, et al. Blood pressure and end-stage renal disease in men. $N$ Engl J Med. 1996;334(1):13-18.

92. Jiang X, Srinivasan SR, Radhakrishnamurthy B, Dalferes ER jr, Bao W, Berenson GS. Microalbuminuria in young adults related to blood pressure in a biracial (black-white) population. The Bogalusa Heart Study. Am J Hypertens. 1994;7(9 Pt 1):794-800.

93. Srinivasan SR, Myers L, Berenson GS. Risk variables of insulin resistance syndrome in African-American and Caucasian young adults with microalbuminuria: the Bogalusa Heart Study. Am J Hypertens. 2000;13(12):1274-1279.

94. Mänttäri M, Tiula E, Alikoski T, Manninen V. Effects of hypertension and dyslipidemia on the decline in renal function. Hypertension. 1995;26(4):670-675.

95. Muntner P, Coresh J, Smith JC, Eckfeldt J, Klag MJ. Plasma lipids and risk of developing renal dysfunction: the atherosclerosis risk in communities study. Kidney Int. 2000;58(1):293-301.

96. Hunsicker LG, Adler S, Caggiula A, et al. Predictors of the progression of renal disease in the Modification of Diet in Renal Disease Study. Kidney Int. 1997;51(16):1908-1919.

97. Bose S, Bomback AS, Mehta NN, et al; KEEP investigators. Dysglycemia but not lipids is associated with abnormal urinary albumin excretion in diabetic kidney disease: a report from the Kidney Early Evaluation Program (KEEP). BMC Nephrol. 2012;13:104.

98. Agrawal V, Shah A, Rice C, Franklin BA, McCullough PA. Impact of treating the metabolic syndrome on chronic kidney disease. Nat Rev Nephrol. 2009;5(9):520-528.

99. Bestermann W, Houston MC, Basile J, et al. Addressing the global cardiovascular risk of hypertension, dyslipidemia, diabetes mellitus, and the metabolic syndrome in the southeastern United States, part II: treatment recommendations for management of the global cardiovascular risk of hypertension, dyslipidemia, diabetes mellitus, and the metabolic syndrome. Am J Med Sci. 2005;329(6):292-305.

100. Gaede P, Vedel P, Parving HH, Pedersen O. Intensified multifactorial intervention in patients with type 2 diabetes mellitus and microalbuminuria: the Steno type 2 randomised study. Lancet. 1999;353(9153):617-622.

101. Hallan S, de Mutsert R, Carlsen S, Dekker FW, Aasarød K, Holmen J. Obesity, smoking, and physical inactivity as risk factors for CKD: are men more vulnerable? Am J Kidney Dis. 2006;47(3):396-405.

102. Finkelstein J, Joshi A, Hise MK. Association of physical activity and renal function in subjects with and without metabolic syndrome: a review of the Third National Health and Nutrition Examination Survey (NHANES III). Am J Kidney Dis. 2006;48(3):372-382.

103. Ibrahim HN, Weber ML. Weight loss: a neglected intervention in the management of chronic kidney disease. Curr Opin Nephrol Hypertens. 2010;19(6):534-538.

104. Chagnac A, Weinstein T, Korzets A, Ramadan E, Hirsch J, Gafter U. Glomerular hemodynamics in severe obesity. Am J Physiol Renal Physiol. 2000;278(5):F817-F822.

105. Kalantar-Zadeh K, Block G, Humphreys MH, Kopple JD. Reverse epidemiology of cardiovascular risk factors in maintenance dialysis patients. Kidney Int. 2003;63(3):793-808.

106. Lindholm A, Bixo M, Björn I, et al. Effect of sibutramine on weight reduction in women with polycystic ovary syndrome: a randomized, double-blind, placebo-controlled trial. Fertil Steril. 2008;89(5):1221-1228. 
107. Filippatos TD, Kiortsis DN, Liberopoulos EN, Georgoula M, Mikhailidis DP, Elisaf MS. Effect of orlistat, micronised fenofibrate and their combination on metabolic parameters in overweight and obese patients with the metabolic syndrome: the FenOrli study. Curr Med Res Opin. 2005;21(12):1997-2006.

108. Kurata A, Nishizawa H, Kihara S, et al. Blockade of Angiotensin II type-1 receptor reduces oxidative stress in adipose tissue and ameliorates adipocytokine dysregulation. Kidney Int. 2006;70(10): 1717-1724.

109. Fried LF, Orchard TJ, Kasiske BL. Effect of lipid reduction on the progression of renal disease: a meta-analysis. Kidney Int. 2001;59(1):260-269.

110. Tonelli M, Wanner C; Kidney Disease: Improving Global Outcomes Lipid Guideline Development Work Group Members. Lipid management in chronic kidney disease: synopsis of the Kidney Disease: Improving Global Outcomes 2013 clinical practice guideline. Ann Intern Med. 2014;160(3):182.
111. Kitiyakara C, Yamwong S, Cheepudomwit S, et al. The metabolic syndrome and chronic kidney disease in a Southeast Asian cohort. Kidney Int. 2007;71(7):693-700.

112. Bakker SJ, Gansevoort RT, de Zeeuw D. Metabolic syndrome: a fata morgana? Nephrol Dial Transplant. 2007;22(1):15-20.

113. Lea JP, Greene EL, Nicholas SB, Agodoa L, Norris KC. Cardiorenal metabolic syndrome in the African diaspora: rationale for including chronic kidney disease in the metabolic syndrome definition. Ethn Dis. 2009;19(2 Supp1 2):S2-S11.

114. Gluba A, Mikhailidis DP, Lip GY, Hannam S, Rysz J, Banach M. Metabolic syndrome and renal disease. Int J Cardiol. 2013;164(2): 141-150.

115. Lea J, Cheek D, Thornley-Brown D, et al; AASK Study Investigators. Metabolic syndrome, proteinuria, and the risk of progressive CKD in hypertensive African Americans. Am J Kidney Dis. 2008;51(5): 732-740.

\section{Publish your work in this journal}

Diabetes, Metabolic Syndrome and Obesity: Targets and Therapy is an international, peer-reviewed open-access journal committed to the rapid publication of the latest laboratory and clinical findings in the fields of diabetes, metabolic syndrome and obesity research. Original research, review, case reports, hypothesis formation, expert opinion and commentaries are all considered for publication. The manuscript management system is completely online and includes a very quick and fair peer-review system, which is all easy to use. Visit http://www.dovepress.com/testimonials.php to read real quotes from published authors. 